\title{
Research on Promotion of the Information Educational Capabilities of Higher Vocational English Teachers under the Mobile-internet
}

\section{Background}

\author{
Gu Guannan ${ }^{1, a}$
}

1Taizhou Polytechnic College, Taizhou city, Jiangsu Province, China, 225300

aemail

Keywords: Information Educational Capabilities, Higher Vocational English Teachers, Mobile-internet Era

\begin{abstract}
Good professional quality plays an important role in English Teaching in higher vocational colleges. However, with the advent of the era of mobile internet, in addition to the professional knowledge, higher vocational English teachers should also have the information educational capabilities. This paper analyzes the concept and characteristics of mobile internet, and puts forward the relevant countermeasures and suggestions for higher vocational English teachers.
\end{abstract}

\section{Concept and Features of Mobile Internet}

Mobile internet is the compound words of the "mobile" and "internet". It refers to the organic integration product of the internet and mobile communication. From a technical perspective, the mobile internet is refers to a kind of belongs to the open nature of the basic telecommunications network, the network can at the same time for the user to provide a variety of services, such as voice services, multimedia services and the core technology of this kind of networks is recognized as broadband; from the point of view of the terminal level, mobile internet has generalized and narrow sense two dimensions defined. In a broad sense, the mobile internet is the mobile terminal that users use mobile phones, tablet computers, to obtain mobile communication network services and internet services through mobile networks. In the narrow sense, it refers to the costumers use the mobile phone terminal, through access to mobile networks, browsing the internet web site information.

Mobile Internet is a product of the development of mobile communication and traditional Internet. It retains the traditional Internet vast amounts of information, open space and convenient to search for advantage, but also makes full use of the mobile communication is quick, convenient, personalized and ubiquitous when the smart phone began to hand a hand, the mobile Internet has gradually integrated into all aspects of life in the public. Through the mobile Internet, the public use of mobile devices such as mobile phones can achieve news online reading, video online watch, music online listening, online games, online entertainment and other functions. Mobile Internet enables the user to use the Internet service in the mobile state, and the mobile terminal has the characteristics of the mobile terminal to facilitate the user to carry and use at any time. Currently 
users in the face of a large number of fragmented times, we often choose to use the mobile Internet to meet the needs of their own entertainment. A lot of people have developed much free time to use their mobile internet habits. The time they use the mobile Internet is far longer than the use time of personal computer.

\section{Requirements of Higher Vocational English Teachers in the Mobile-internet Era}

The information teaching abilities of higher vocational education are guided by the advanced educational concept and the internet information resources. It is not only the core content of the information construction of higher vocational education, but also the inevitable requirement of teacher professional development in the era of big data. Application of the characteristics of higher vocational education requires teachers of higher vocational education in teaching design and evaluation process to master and professional related all kinds of educational information technology and combined with the characteristics of professional teaching, in order to achieve the teaching process optimization. Higher vocational teachers' active the modern educational technology and all kinds of professional characteristics of organic integration of informationization teaching ability, not only can the complicated professional knowledge to vivid form of dynamic or pictures to students display, enrich the teaching contents, excellence in learning environment, improve teaching effect and increase students' knowledge of effective memory time; further improve the teachers' comprehensive competitiveness, accelerate the professional development of teachers, innovative teaching methods, promote education informatization, to deepen the reform of education and teaching contribute. Some English teachers actively use information technology in the classroom, but when asked about the reasons, some said that in order to attract the attention of students, some said that the school requirements. And when asked if there is a right and a wrong way to use of information technology, the use of information technology should follow a certain principle, between information technology and curriculum objective relationship. Obviously, in the use of information technology, teachers are not clear objectives. They are non - non - non principles, and they are not clear about the relationship between the information technology and the teaching objectives of the course. With the rapid development of information technology, more and more information technology into classroom teaching, teaching environment is more and more tend to digital. At the same time, the integration of mobile internet technology and English subjects is constantly advancing to the deep level, the English teachers' classroom teaching skills have been given a new connotation and characteristics. Therefore, it is a new requirement for English teachers to improve the English teachers' information abilities is in the mobile internet era.

\section{Practical Information Educational Capabilities of Higher Vocational English Teachers}

Two-demensinal Code. Two-dimensional code can have different applications in different subjects. In terms of English subject, listening, vocabulary, grammar, reading, writing and other content are important and difficult to learn. Teachers can put listening comprehension materials associated into class space or teachers' personal space. It will generate a two-dimensional code, the two-dimensional code affixed to the corresponding parts of books and exercise books, students can listen selectively their weak link. Teachers can also be vocabulary memory method is made into a micro course, two-dimensional code generation, print to the students, attached to the fixed textbook place, teachers don't always to be printed to text narrative is unable to achieve the teaching effect. In some aspects of the classroom teaching can be realized through the two-dimensional code. Teachers can according to the degree of difficulty of the knowledge of the self-made two-dimensional code 
exercises, supporting not only, and no any charge. The English teachers in higher vocational colleges can be personalized layout homework and made into a two-dimensional code, students only need to scan by watching micro course, finish the homework easily complete the consolidation of knowledge. Two dimensional code data feedback in a timely manner, so that students more like the classroom interaction. In practice, we found that in the interaction in the classroom, the two-dimensional code data collection and feedback, competition among students awareness increased; with the help and encouragement of English teachers in higher vocational colleges, students' interest in learning more strong. At the same time, higher vocational English teachers in accordance with the data of the targeted explanation, reward and so on is to let the students feel that they are concerned about. The learning interest of the students will enter a virtuous cycle, with the natural result of enhancing academic performance.

Wechat. WeChat is a real-time chat application launched by Tencent Inc in 2011. Users can quickly send voice, video, pictures, and text via the WeChat client on a mobile phone or tablet. WeChat public subscription number and service number in the mass. Resources, can be shared with others quickly; circle of friends can be shared resources can also interact; more group chat and real-time intercom to achieve the exchange of zero distance. In order to make the English teaching more creative and more personalized. At the same time, it combines the advantages of WeChat software and the teaching goal of English as the ability to cultivate. WeChat can provide learning platform. English teachers in higher vocational colleges can be self instructional video series on two-dimensional code, indicate the contents of, paste in the classroom, the students by phone or tablet computer scanning can enter the page watch related video; vocational English teachers can also by focusing on some micro letters to the public, and students share inside the related learning resources. Before the students begin to study, the English teachers in higher vocational colleges should be prepared to do a good job. The first is to establish a class learning community. Due to the micro channel is an online platform. Each of the students on the phone or tablet computer installed micro channel client, choice to student number and name for the user name to apply for an account. English teachers in higher vocational colleges set up to the class and discipline named group, and the group of code is pasted on the walls of the classroom dedicated to open a two-dimensional code area, for every student of the scanning. After the addition of the crowd, students can quickly through the group to add friends, each learning group can also build a small group of convenient exchange. In the classroom, the higher vocational English teachers should sort out the general problems reflected in the discussion of the former group. Again in view of the characteristics of English subjects, it's useful that the students use more time to say and listen.

Micro-blog. As a internet social networking tool, micro-blog is the hallmark of mobile internet era the. It allows users to update their status with a short text anytime and anywhere. The length of each piece of information is limited in 140 characters, supportting for images, audio, video, super links and other multimedia content, and support users through the computer, mobile phone, instant communication tools, and other terminal visits. At the beginning of the beginning of micro-blog teaching, it is inevitable to transfer or adaptation, integration of information and other means to explore, familiar with the new teaching environment. But if the release of micro-blog's long-term confined to others reproduced news, it will only succeed and lopsided. The reason why a micro-blog user attention is entirely derived from the original content of its content. Micro-blog supports a variety of formats of materials, so in the rendering of authentic, faithful corpus, can be used to make up for the lack of textbooks. It is undeniable that the network has broken the boundaries of cultural exchanges, a large number of western countries, to show the lives of these countries are expected to readily available. These multimedia materials have the characteristics of 
image, motivation, the most important is to create a language environment close to life, there is the use of the natural environment for students to create immersion. Using micro-blog to carry on the language teaching to the teacher's comprehensive quality condition has put forward the higher request. Teachers should have a more objective understanding of their own language and computer knowledge, personality characteristics and other aspects of the situation, and combined with the specific circumstances of the audience, flexible customized teaching strategies suitable for both teachers and students. Micro-blog is to share, in the micro-blog platform, the mutual concern between friends can freely forward and comment on micro-blog, micro-blog's function can be applied to public English teaching. The teachers and students can register the microblog and mutually "follow". They can discuss a topic in English. The microblog provide students with a English practice opportunity.

Applications relevant with English Learning. The intelligent and portable property of cellphone, combined with rich APP software resources, make English learning easier and more interesting. At present, the word class APP is most popular in all kinds of English learning resources. The downloads of Baicizhan, Word Plus are more than 10 million. Due to the development and application of speech recognition technology, oral English class. A new force suddenly rises. in recent years. They also show that the A new force suddenly rises. learners for the urgent desire to improve my oral english. Fluent in English and speak English more similar in the main function, both provide authentic American English, through the man-machine dialogue, to achieve interaction: the user first through dialogue to imitate oral practice, speech recognition and evaluation of advanced technology for the learners will word for word and sentence for sentence, real-time scoring, skilled practice, can begin to pass through, the system will finally provide the overall score, the standard can be upgraded to learn further other courses: all courses focused on the content of the system and advanced, according to the scene classification, covering life, business, workplace, tourism, and set a different level of difficulty, and each course selection of vocabulary, help learning focus difficult words: scene content design modular, making a complete oral practice in just a few minutes, the learner can at any time To use the time of fragmentation. Vocational English teachers should take the initiative to study, use and recommend such APP to students to provide a powerful tool for English learning.

\section{Conclusion}

Under the background of the mobile internet, English teachers in higher vocational colleges should give adequate attention to the profound impact of mobile internet on education, enhance the ability of information technologies and improve the interest and practicability of English teaching to transmit application-oriented talents with good English ability for the society.

Acknowledgements

2016 key vocational research program of Taizhou Polytechnic College, ZY201602, project director: Gu Guannan.

\section{References}

[1] Zhan Yufen, Liu Zhibing, Contemporary Vocational Education, Vol. 6 (2015) No 9, p.97-99

[2] Yong Jiye, Health Vocational Education, Vol. 34 (2016) No 7, p.40-42

[3] Wang Peng, Xu Yanping, Career Horizon, Vol. 10 (2014) No 6, p.31-33 
[4] Liu Guojun, Journal of Harbin Vocational \& Technical College, Vol. 24 (2013) No 6, p.26-27

[5] Chen Gangni, The Chinese Journal of ICT in Education, Vol. 22 (2016) No 4, p.75-77

Gu Guannan(1981- ), female, Taizhou, Jiangsu Province,China, lecturer, master's degree, applied linguistics and English teaching. 